\title{
INSPECTION AND REPAIR DECISIONS FOR HYDRAULIC STRUCTURES UNDER ISOTROPIC DETERIORATION
}

\author{
Jan M. van Noortwijk, Delft University of Technology, NL \\ Roger M. Cooke, Delft University of Technology, NL \\ Matthijs Kok, Delft Hydraulics, Emmeloord, NL
}

The subject of study is minimising the cost of inspection and repair of a hydraulic structure. The optimisation is based on isotropic properties of the underlying physical deterioration process. Probabilities of preventive repair and failure are obtained conditional on the only available (subjective) information, i.e. the average damage with regard to a finite or an infinite time-horizon. Hereby it is assumed that the damages per time-unit are exchangeable and that the decision-maker is cognitively indifferent to the way information about the average damage is gathered. By introducing a prior we can account for uncertainty in the decision problem. Advantages of our Bayesian approach are that we base our mathematical models on an observable quantity, namely the damage, and that our results can be expressed explicitly conditional on the average damage. For more details see van Noortwijk [1] and van Noortwijk, Cooke \& Kok [2].

One illustration from the field of hydraulic engineering is studied: determining a cost-optimal periodic frequency of inspecting the concrete-weighted erosion mats of the Eastern Scheldt barrier. The mats are under water and must ensure the stability of the barrier. Failure occurs when a scour hole arises and its depth exceeds a certain safety level.

\section{References}

[1] Jan M. van Noortwijk. Inspection and repair decisions for hydraulic structures under symmetric deterioration. Technical Report ESRC 92-17, University of California at Berkeley, U.S.A., June 1992.

[2] Jan M. van Noortwijk, Roger M. Cooke, and Matthijs Kok. A Bayesian failure model based on isotropic deterioration. European Journal of Operational Research (to appear), 1994. 